\title{
Microstructure Characterization and Thermal Stability of Nanocrystalline Cu Powders Processed via Cryomilling
}

\author{
Jingchun Liu ${ }^{1}$, Hua Cui ${ }^{2}$, Xianglin Zhou ${ }^{1}$ and Jishan Zhang ${ }^{1, *}$ \\ ${ }^{1}$ State Key Laboratory for Advanced Metals and Materials, University of Science and Technology Beijing, \\ Beijing, 100083, P. R. China \\ ${ }^{2}$ School of Materials Science and Engineering, University of Science and Technology Beijing, Beijing, 100083, P. R. China
}

Nanocrystalline $\mathrm{Cu}$ powders with a grain size of about $32 \mathrm{~nm}$ have been successfully synthesized using cryomilling technique. The effect of cryomilling time on the particle size, grain size, and structure of cryomilled $\mathrm{Cu}$ powders were investigated. The thermal stability of cryomilled $\mathrm{Cu}$ powders was studied and the study described the enthalpy change due to grain growth and stress relaxation of cryomilled Cu particles by annealing. The stress relaxation process associated with reordering of the grain boundaries was found to occur at $280^{\circ} \mathrm{C}$. The grain growth process was found at $330^{\circ} \mathrm{C}$ and the thermal release of the grain growth was detected by differential scanning calorimetry analysis. [doi:10.2320/matertrans.M2011374]

(Received December 6, 2011; Accepted January 10, 2012; Published March 7, 2012)

Keywords: copper, nanostructures, transmission electron microscopy, differential scanning calorimetry

\section{Introduction}

Nanostructured materials, characterized by a microstructural length scale of 1 to $100 \mathrm{~nm}$, have received considerable scientific attention and technological interest because the small grain size can result in notable improvements in mechanical, magnetic, optical and other physical properties. ${ }^{1,2)}$ Cryomilling, originally developed to process nanophase dispersion strengthened aluminum alloys, is a high/ low energy mechanical milling technique, by which elemental and/or prealloyed powders are milled in cryogenic media, e.g., liquid nitrogen, liquid argon, etc., to form a slurry. ${ }^{3,4)}$ Nanocrystalline materials produced by cryomilling have the advantage of smaller crystallite sizes, more homogeneous microstructure and also higher thermal stability compared to other techniques. Extensive studies have been performed on the evolution of the microstructure by cryomilling of single-phase powders and atomized powders. ${ }^{5-8)}$ The evolution of microstructure is coupled to the mechanical properties of the powders. Understanding of the microstructure evolution is therefore critical to the understanding of the alloy behavior. ${ }^{9)}$ Thermal stability is another facet of the alloy under service. Understanding the thermal stability of the cryomilled powders is important for their potential application. Recently, the enhanced grain stability of cryomilled powders was reported in diverse alloy systems, such as pure $\mathrm{Al},{ }^{10)}$ pure $\mathrm{Ni},{ }^{11)} \mathrm{TiAl}^{12)}$ and $\mathrm{PdZr} .{ }^{13)}$

Previous studies have failed to detect the thermal effect of the grain growth owing to the limited accuracy of the calorimeter. ${ }^{14,15)}$ In present study, we detected the thermal release of the grain growth based on differential scanning calorimetry (DSC) analysis. The object of this study was to investigate the microstructure evolution and thermal stability of $\mathrm{Cu}$ powders produced by cryomilling.

\section{Experimental Procedure}

The starting powder used for this work was a commercial

${ }^{*}$ Corresponding author, E-mail: zhangjs@ skl.ustb.edu.cn water-atomized Copper ( 99.81 mass\% purity) powder. The copper powder particles have spherical-like shape and in the size range from 5 to $50 \mu \mathrm{m}$. The milling of $\mathrm{Cu}$ powders was conducted at the rate of $200 \mathrm{rpm}$ for $12 \mathrm{~h}$ under a liquid nitrogen environment. The temperature in the vial was between -160 and $-193^{\circ} \mathrm{C}$. The stainless steel balls of $6.4 \mathrm{~mm}$ in diameter were used as the grinding media, and the ball-to-powder weight ratio was $30: 1$. The process details on the cryomilling can be found elsewhere in the literature. ${ }^{16)}$

The morphology observation of the powders were conducted using a ZEISS SUPRA55 scanning electron microscope (SEM). Particle size distribution was conducted using a SEISHIN LMS-30 laser scattering with ethanol as the scattering media. Microstructure analysis of the as-milled powder was performed using a Hitachi H-800 and JEM-2010 high resolution transmission electron microscope (HRTEM) with an acceleration voltage of $200 \mathrm{kV}$. The TEM sample of powders was prepared using the carbon grid method. ${ }^{17)} \mathrm{X}$-ray diffraction (XRD) analysis was performed in the $2 \theta$ range of 10 to $100^{\circ}$ using $\mathrm{Cu} \mathrm{K} \alpha(\lambda=0.15406 \mathrm{~nm})$ radiation in a Rigaku DMAX-RB 12KW diffractometer equipped with a graphite monochromator. After the component of $\mathrm{K} \alpha_{2}$ was corrected, the peak data, e.g. the full width at half maximum, of diffraction peaks were measured using a software package in the diffractometer. In the present study, fully annealed pure copper powders were selected as standard samples for the determination of instrumental broadening. The calculation of grain size and microstrain based on the XRD data was conducted by the Integral Breadth method, assuming a Cauchy-Gaussian profile of the reflection, ${ }^{18)}$

$$
\frac{(\delta 2 \theta)^{2}}{\tan ^{2} \theta_{0}}=\frac{K \lambda}{L}\left(\frac{\delta 2 \theta}{\tan \theta_{0} \sin \theta_{0}}\right)+16 e^{2}
$$

in which $K$ is a constant taken as 1 , where $\theta_{0}$ is the position of the analyzed peak maximum, $\lambda$ the $\mathrm{X}$-ray wave length, $L$ is the crystallite size, $e$ is the maximum strain, and $\delta 2 \theta=$ $\mathrm{B}\left(1-b^{2} / B^{2}\right), b$ and $B$ are the breadths in radians of the same peak in the reference and experimental patterns, respectively. Any available orders of a given reflection may be used to construct a linear plot of $(\delta 2 \theta)^{2} / \tan ^{2} \theta_{0}$ against 


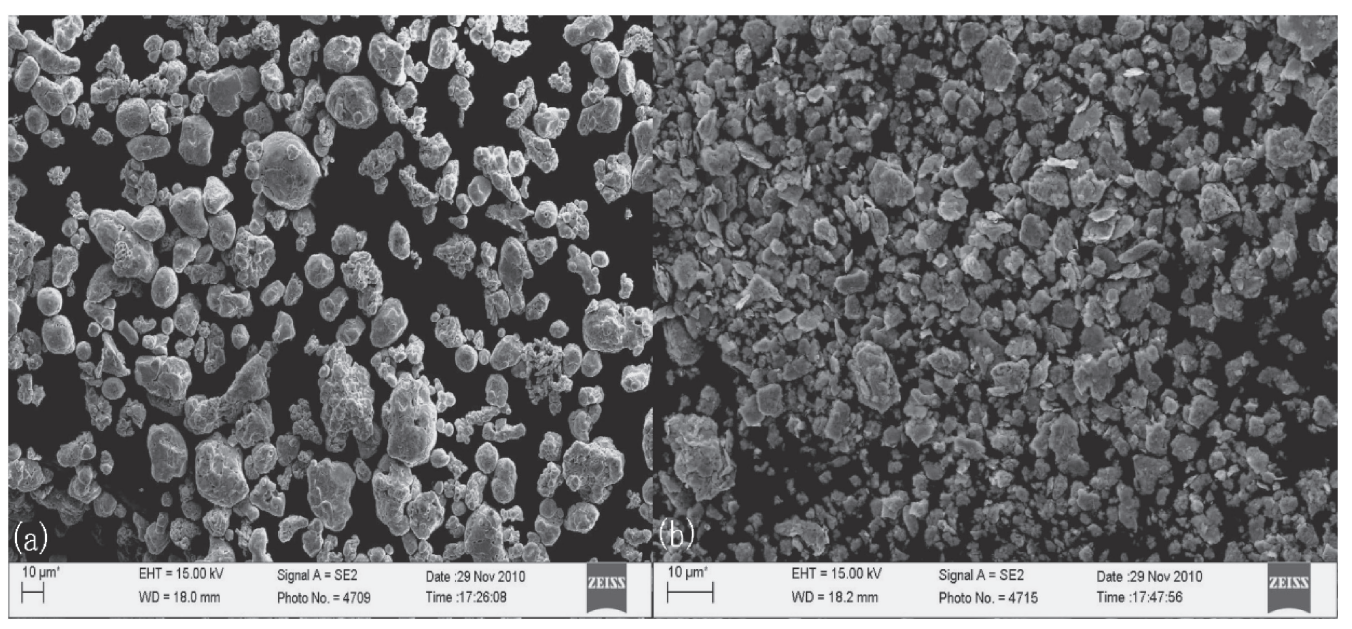

Fig. 1 SEM morphology of the starting $\mathrm{Cu}$ powders (a) and as-cryomilled $\mathrm{Cu}$ powders (b).

$(\delta 2 \theta) /\left(\tan \theta_{0} \sin \theta_{0}\right)$. From the slope, $\lambda / L$ and ordinate intercept $16 e^{2}$, the crystallite size, $L$, and strain, $e$, may be determined.

To verify the thermal stability of the cryomilled powders, samples sealed in quartz tube were isothermally annealed in a box furnace at 280 and $330^{\circ} \mathrm{C}$ for $30 \mathrm{~min}$ and were characterized for grain size.

Thermal analysis was performed with a differential scanning calorimeter (DSC Q2000, TA Instruments, Inc.). The DSC samples (approx. 20.26 mg) were run in Al pans with tightly-fitted inverted lids at constant heating rates in a flowing $\mathrm{N}_{2}$ atmosphere.

\section{Results and Discussion}

Figures 1(a) and 1(b) showed atomized $\mathrm{Cu}$ powders and cryomilled $\mathrm{Cu}$ powders, respectively. These images indicated that the starting $\mathrm{Cu}$ powders had spherical shape with a size of approximately $24 \mu \mathrm{m}$, however, cryomilling for $12 \mathrm{~h}$ generated irregularly shaped $\mathrm{Cu}$ particles/agglomerates with a size of approximately $7 \mu \mathrm{m}$. It was generally acknowledged that cryomilling could result in micron-sized powder particles/agglomerates attributing to the continuous flattening, welding and fracturing of the powder particles during the cryomilling process. ${ }^{4}$

Figure 2 displayed XRD patterns of the starting and cryomilled powders. The initially sharp diffraction peaks of fcc $\mathrm{Cu}$ phase became significantly broadened after the cryomilling due to the refinement of grain size and the introduction of lattice strain. The calculation of grain sizes based on the XRD data was conducted by the Integral Breadth method, and the grain size values was between 20 to $55 \mathrm{~nm}$. The formation of nanostructure by cryomilling was demonstrated in many previous studies. ${ }^{5,8,19)}$

The average grain size and mean microstrain measured from the X-ray diffraction line broadening during the cryomilling process was illustrated in Fig. 3. The average grain size and mean microstrain of the $12 \mathrm{~h}$ milled powders were $24 \mathrm{~nm}$ and $0.41 \%$, respectively.

To obtain further information about the microstructure of the cryomilled powders, the as-cryomilled powders were investigated by TEM. Figures 4(a) and 4(b) show a bright-

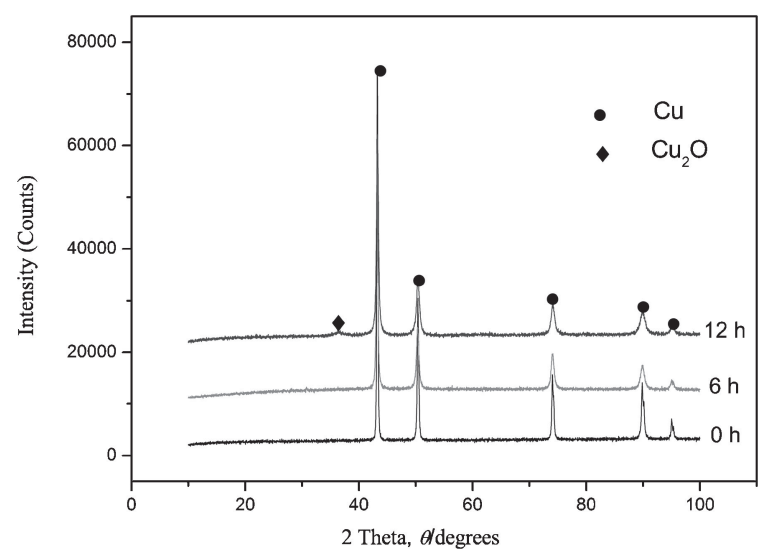

Fig. 2 XRD patterns of cryomilled $\mathrm{Cu}$ powders for different milling times.

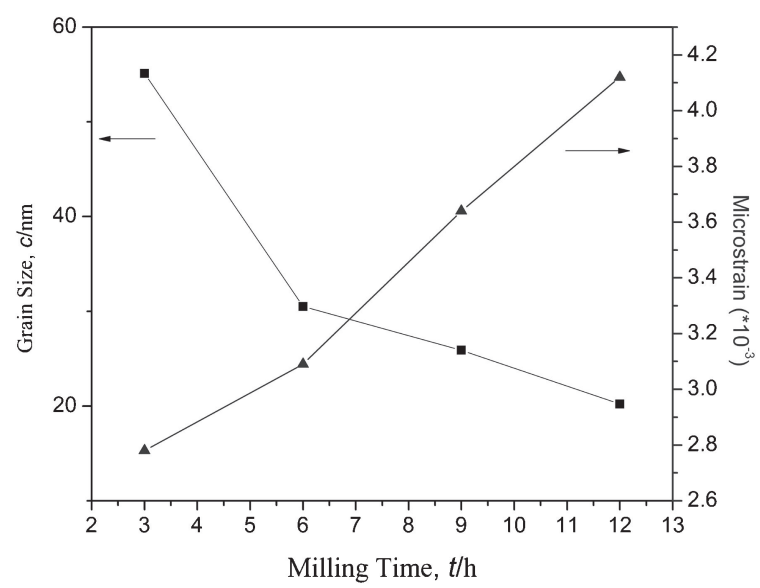

Fig. 3 The mean grain size and microstrain of the $12 \mathrm{~h}$ cryomilled $\mathrm{Cu}$ samples.

field image and the corresponding selected area electron diffraction (SAED) pattern, respectively. Typical grains observed were equiaxed-like and the average grain size was $32 \mathrm{~nm}$, being consistent with the results from our XRD measurements. As shown in Fig. 4(b), the SAED pattern of the $\mathrm{Cu}$ grains shows a ring pattern, indicating that the individual grains are separated by high-angle grain boundaries and have a random orientation with neighboring grains. 

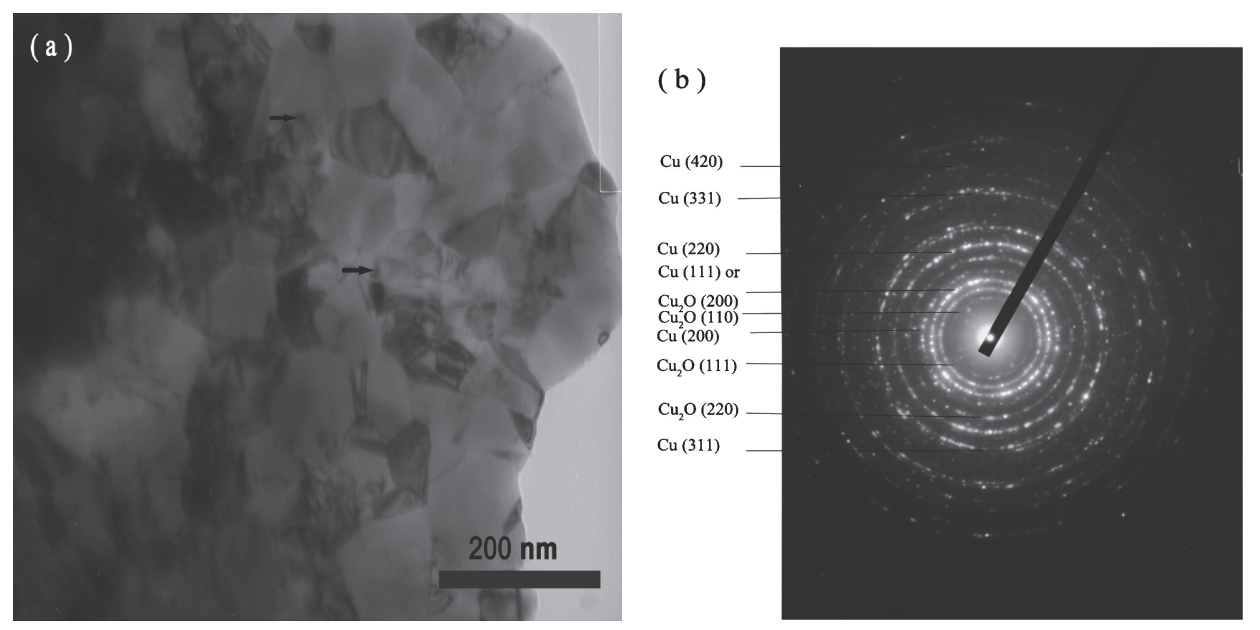

(c)

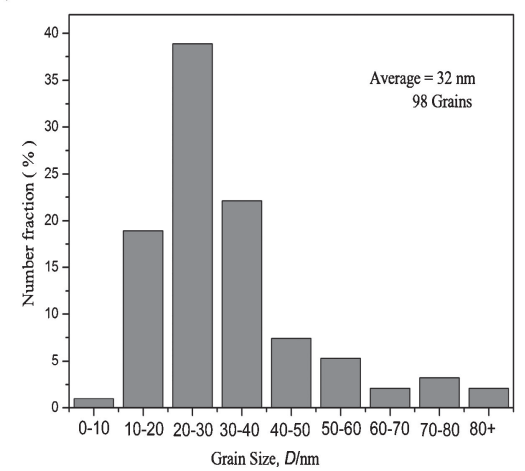

Fig. 4 Bright-field TEM image (a) and SAED pattern (b) of the $12 \mathrm{~h}$ cryomilled $\mathrm{Cu}$ powder, revealing a nanocrystalline grain structure in the powder. (c) The distribution of grains measured from the bright field images.

The average grain size shown in Fig. 4(c) is about $32 \mathrm{~nm}$. It is interesting that the TEM bright-field image for the milled $\mathrm{Cu}$ powders shows ultrafine particles with a size less than $5 \mathrm{~nm}$ [as indicated by the arrows in Fig. 4(a)] as well as $\mathrm{Cu}$ nanograins. From the SAED pattern, these fine particles were identified as $\mathrm{Cu}_{2} \mathrm{O}$. It should be pointed out that it was difficult to produce bright-field images exclusively from the reflections from the oxide particles because of the close spacing of the ring patterns.

The formation of these fine oxide particles was considered as a result of interaction between $\mathrm{Cu}$ and $\mathrm{O}$ from the surrounding environment under the energetic milling conditions. During cryomilling, the microstructural evolution followed the well-known stages of a mechanical alloying process: flattening, fracturing, and welding of constituent materials. ${ }^{3,4)}$ The large amount of surface area of the freshly cryomilled powders resulted in extremely high reactivity. Furthermore, the high surface area associated with the cryomilled powders was likely to enhance chemical reactions that occur during cryomilling. ${ }^{11)}$

Figure 5 showed the XRD pattern of the as-cryomilled $\mathrm{Cu}$ in comparison with those of the as-annealed $\mathrm{Cu}$ powders. As can be clearly seen, the intensity of $\mathrm{Cu}$ peaks in XRD patterns increased and narrowed sharply after annealing for one hour. The strain prior to annealing was $0.41 \%$. At heat treatment temperature above $330^{\circ} \mathrm{C}$, strain could not be detected utilizing the integral breadth technique. The lack of strain at temperatures above $330^{\circ} \mathrm{C}$ made clearly that a restructuring of the grain boundaries or a grain growing

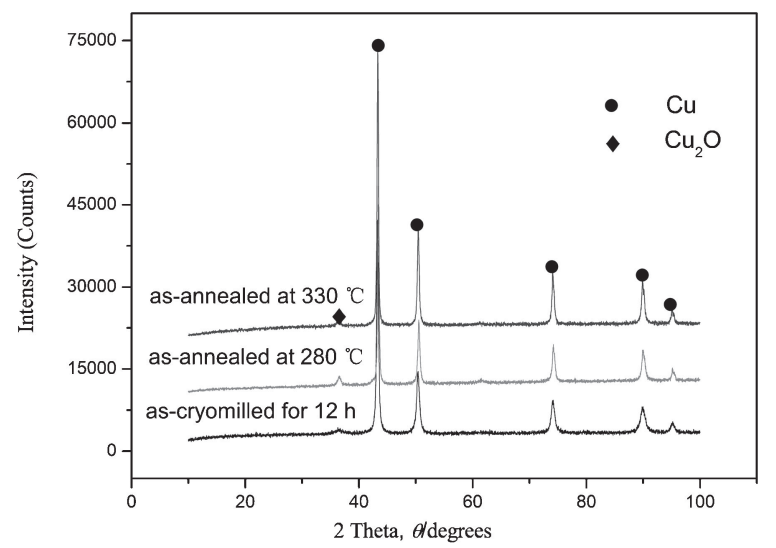

Fig. 5 X-ray diffraction patterns of as-milled powders annealed for $30 \mathrm{~min}$ at 280 and $330^{\circ} \mathrm{C}$.

process of highly unstable grains, which led to a more stable structure above $330^{\circ} \mathrm{C} .^{20}$ ) In addition, the reflection from $\mathrm{Cu}_{2} \mathrm{O}$ was still existed after annealing for one hour, which may indicate $\mathrm{Cu}_{2} \mathrm{O}$ could be thermally stable.

The thermal effect observed in the cryomilled $\mathrm{nc} \mathrm{Cu}$ was very different from that in the conventional coarse-grained $\mathrm{Cu}$. A comparison of DSC signals between the $\mathrm{nc} \mathrm{Cu}$ and the conventional coarse-grained polycrystalline $\mathrm{Cu}$ was shown in Fig. 6. For the conventional $\mathrm{Cu}$ samples, no clear exothermic reaction was observed. For the cryomilled $\mathrm{nc} \mathrm{Cu}$ samples, two clear exothermic reaction was observed. The exothermic 




Fig. 6 DSC curves of the cryomilled and conventional $\mathrm{Cu}$ powders at a heating rate of $10^{\circ} \mathrm{C} \mathrm{min}^{-1}$.

reactions for the cryomilled samples may be attributed to the microstrain release process and the grain growth process as well, which was confirmed by XRD results shown in Fig. 4. After annealing at $280^{\circ} \mathrm{C}$, the microstrain could not be detected using the integral breadth technique. The lower temperature peak was at about $280^{\circ} \mathrm{C}$, the higher temperature peak was at about $330^{\circ} \mathrm{C}$. The exothermic heat associated with the lower temperature (at about $330^{\circ} \mathrm{C}$ ) peak was calculated from the area under the peak. The stored enthalpy increased to a maximum of $5.96 \mathrm{~J} / \mathrm{g}$. The first exothermic peak was perhaps the easiest to explain. There has been much discussion that nanostructured materials undergo three processes, namely, recovery, recrystallization, and grain growth during heating. This dramatic decrease in the strain combined with the relatively little increase in grain growth for the first exothermic peak ( 37 to $44 \mathrm{~nm}$ ) indicated that this first exothermic peak can be associated with the stress relaxation and reordering of the grain boundaries. Some literatures ${ }^{20,21)}$ found that the exothermic peak at a lower temperature which they attributed to energy released when randomly oriented grain boundaries were transformed to ordered grain boundaries and with the advent of a recovery process in which the grain boundaries became more clearly delineated and the dislocation density within the grains was reduced.

The second DSC peak at a higher temperature may be due to dislocations removed in the larger grains during the annealing process. The enthalpy release of the higher exothermic peak has been determined to be approximately $6.40 \mathrm{~J} / \mathrm{g}$.

Isothermal annealing treatment of the as-milled powder at 280 and $330^{\circ} \mathrm{C}$ showed that the as-milled disordered structure became ordered and strain relaxation after annealing at $280^{\circ} \mathrm{C}$ by the level of lattice strain decreased from about $0.41 \%$ (asmilled) to $0.27 \%$ after annealing at $280^{\circ} \mathrm{C}$. Considering the sluggish grain growth by annealing at $330^{\circ} \mathrm{C}$, the majority of the heat release below $280^{\circ} \mathrm{C}$ was supposed to be produced by reordering and strain release processes. The isothermal annealing treatment showed three kinds of structural evolution: reordering, strain relaxation and grain growth. The reordering and strain relaxation processes were completed during the first exothermic peak. The sluggish grain growth has been attributed to both intrinsic and extrinsic sources. Intrinsic factors, such as random orientation of neighboring grains or reorientation of random atoms in disordered grain boundaries, may incubate the grain growth until some mechanisms operates to favor grain growth. ${ }^{22)}$

\section{Conclusions}

Nanocrystalline $\mathrm{Cu}$ powders was synthesized using cryogenic mechanical milling at liquid nitrogen temperature. The average particle size initially decreased from the original 24 to $7 \mu \mathrm{m}$ after $12 \mathrm{~h}$ of milling. The microstructure of the powders was consisted of irregular grains with average grain size of about $32 \mathrm{~nm}$. The cryomilled powder demonstrated good thermal stability below $330^{\circ} \mathrm{C}$. The $\mathrm{Cu}_{2} \mathrm{O}$ scale presented an obstruction to the grain boundary migration. The thermal effect of the grain growth has been detected by DSC analysis.

\section{Acknowledgment}

The authors wish to acknowledge financial support provided by the National Natural Science Foundation of China under grants No. 50874009 and No. 50871019.

\section{REFERENCES}

1) H. Gleiter: Prog. Mater. Sci. 33 (1989) 223-315.

2) M. A. Meyers, A. Mishra and D. J. Benson: Prog. Mater. Sci. 51 (2006) 427-556.

3) E. J. Lavernia, B. Q. Han and J. M. Schoenung: Mater. Sci. Eng. A 493 (2008) 207-214.

4) D. B. Witkin and E. J. Lavernia: Prog. Mater. Sci. 51 (2006) 1-60.

5) B. Yang, J. Z. Fan, B. Hao, X. F. Tian, J. S. Cheng and J. S. Zhang: Rare Met. 26 (2007) 147-151.

6) G. Lucadamo, N. Y. C. Yang, S. C. Marchi and E. J. Lavernia: Mater. Sci. Eng. A 30 (2006) 230-241.

7) B. Ahn, R. Mitra, E. J. Lavernia and S. R. Nutt: J. Mater. Sci. 45 (2010) 4790-4795.

8) J. Milligan, R. Vintila and M. Brochu: Mater. Sci. Eng. A 508 (2009) $43-49$.

9) B. Q. Han, J. Ye, F. Tang, J. Schoenung and E. J. Lavernia: J. Mater. Sci. 42 (2007) 1660-1672.

10) F. Zhou, J. Lee and E. J. Lavernia: Scr. Mater. 44 (2001) 2013-2017.

11) J. Lee, F. Zhou, K. H. Chung, N. J. Kim and E. J. Lavernia: Metall. Mater. Trans. A 32 (2001) 3109-3115.

12) M. Kambara, K. Uenishi and K. F. Kobayashi: J. Mater. Sci. 35 (2000) 2897-2905.

13) B. K. VanLeeuwen, K. A. Darling, C. C. Koch, R. O. Scattergood and B. G. Butler: Acta Mater. 58 (2010) 4292-4297.

14) L. Lu, N. R. Tao, L. B. Wang, B. Z. Ding and K. Lu: J. Appl. Phys. 89 (2001) 6408-6414

15) L. Lu, M. L. Sui and K. Lu: Acta Mater. 49 (2001) 4127-4134.

16) K. Tao, X. L. Zhou, H. Cui, H. B. Chen, Y. B. Li and J. S. Zhang: Int. J. Min. Met. Mater. 16 (2009) 77-83.

17) J. H. He and J. M. Schoenung: Mater. Sci. Eng. A 336 (2002) 274-319.

18) Z. Zhang, F. Zhou and E. J. Lavernia: Metall. Mater. Trans. A 34 (2003) 1349-1355.

19) C. Goujon, P. Goeuriot, P. Delcroix and G. Le Caër: J. Alloy. Compd. 315 (2001) 276-283

20) V. L. Tellkamp, S. Dallek, D. Cheng and E. J. Lavernia: J. Mater. Res. 16 (2001) 938-944.

21) J. Wang, Y. Iwahashi, Z. Horita, M. Furukawa, M. Nemoto, R. Z. Valiev and T. G. Langdon: Acta Mater. 44 (1996) 2973-2982.

22) K. W. Liu and F. Mücklich: Acta Mater. 49 (2001) 395-403. 